\title{
BIOSURFACTANTS' PRODUCTION FROM RENEWABLE NATURAL RESOURCES: EXAMPLE OF INNOVATIVEAND SMART TECHNOLOGY IN CIRCULAR BIOECONOMY
}

\author{
Surekha K. SATPUTE ${ }^{1}$, Grażyna A. PŁAZA², Arun G. BANPURKAR ${ }^{1}$ \\ Savitirbai Phule Pune University ${ }^{1}$, \\ Silesian University of Technology ${ }^{2}$
}

\begin{abstract}
:
A strong developed bio-based industrial sector will significantly reduce dependency on fossil resources, help the countries meet climate change targets, and lead to greener and more environmental friendly growth. The key is to develop new technologies to sustainably transform renewable natural resources into bio-based products and biofuels. Biomass is a valuable resource and many parameters need to be taken in to account when assessing its use and the products made from its. The bioeconomy encompass the production of renewable biological resources and their conversion into food, feed and bio-based products (chemicals, materials and fuels) via innovative and efficient technologies provided by industrial biotechnology. The paper presents the smart and efficient way to use the agro-industrial, dairy and food processing wastes for biosurfactant's production. Clarification processes are mandatory to use the raw substrates for microbial growth as well as biosurfactant production for commercial purposes. At the same time it is very essential to retain the nutritional values of those cheap substrates. Broad industrial perspectives can be achieved when quality as well as the quantity of the biosurfactant is considered in great depth. Since substrates resulting from food processing, dairy, animal fat industries are not explored in great details; and hence are potential areas which can be explored thoroughly.
\end{abstract}

Key words: bio-based industries, renewable natural resources, biosurfactants, innovation technology, bioeconomy

\section{INTRODUCTION}

The European Union (EU) is set to make legislative proposals that would break away from the traditional linear economic model of make-use-dispose, in favors of a circular and regeneration model that uses resources in a smart and efficient way. This could turn the waste into new resourceful products through considering its sustainability and circularity in the design of products and processes [1]. In December 2015, the European Commission laid the foundation stone for establishing a "circular economy". The strategy is focused on the waste prevention or when it is generated can be utilized for bioeconomical ways. Particularly, biorefineries have been proved to be the efficient one to treat and/or process the waste. Subsequently, biorefineries offers the sustainable ways towards the principles of a "zero waste» society [2, 3]. The document entitled "European Biorefinery 2030 Vision" [4] provides the information and tools to enable policy makers to build a framework for the development of a sustainable knowledgebased European bioeconomy, with a network of biorefineries playing an essential role. Biorefining is the sustainable processing of biomass into a spectrum of marketable products and energy $[5,6]$. In other words, biomass is sustainably used as a resource for production of among others heat, power, fuels, chemicals and materials. An important stage in biorefinery system is the provision of a renewable, consistent and regular supply of feedstocks [3, 7]. Biomass feedstocks are classified into two main categories: (1) dedi- cated feedstocks (like sugar crops, i.e., sugarcane; starch crops, i.e. sweet sorghum; lignocellulosic crops, i.e., switchgrass; oil crops, i.e., soya, jatropha; grass crops, i.e., grass sillage; marine crops, i.e. seaweed) and (2) residues/by products (oil-based residues, i.e., waste cooking oil, tallow; lignocellulosic residue, i.e., rice husks, tomato pomace, logging residue; industrial organic residues, i.e., manure; domestic organic residue). Organic wastes mainly composed by agriculture waste, yard and forestry waste, sludge, food processing waste and organic house-hold waste are available in large amounts in Europe, and they are being used in smart way [8]. As presented each citizen in the EU produces $481 \mathrm{~kg}$ of household waste annually - around 224 million tonnes a year [9]. According to the analysis, recycling and incinerating the more than 2.5 billion tonnes of waste produced yearly in Europe currently captures only about $5 \%$ of the original raw material value. In the economic terms, it is important to highlight that the use of renewable substrates offers great completion with other markets. With this point of view, the paper deals with the application of various agro-industrial wastes for biosurfactants' production.

\section{BIOSURFACTANTS VS SURFACTANTS}

World-wide interest in biosurfactants significantly increased in the recent years due to their ability to mitigate most requirements of chemical surfactants. Advances in the era of industrial globalization have increasingly directed several industries towards biotechnology. While the world 
market for biotechnology products was US $\$ 1.7$ billion in 1992, it has increased beyond US $\$ 500$ billion. Surfactants constitute an integral part of chemical feedstock inventory to many industries and are mainly synthesized from petrochemicals. Their world - wide production was estimated to exceed four million tonnes and by $\$ 9-10$ billion per year [10]. The market for biosurfactants was $2210 \mathrm{mln}$ US dollars in 2011 and it will grow from 2011 to 2018 at a rate of $3.5 \%$. Huge global surfactant market is opened to generate great revenues [11].

The term surfactant (SURFace ACTive AgeNTS) includes a wide variety of compounds, both synthetic and biological, but all of which have similar tension active properties [12, 13]. Biosurfactants (biological surface active compounds or microbial surface active agents) are the biomolecules produced by living cell, mainly by microorganisms. They are amphiphilic biochemical compounds contained both hydrophobic and hydrophilic groups that allow them to exist at the interface between polar and nonpolar media. They are produced on microbial cell surfaces or secreted as extracellular products. Structurally, they contain a hydrophilic moiety which can be a carbohydrate, amino acid, cyclic peptide, phosphate, carboxylic acid or an alcohol and a hydrophobic moieties either a long - chain fatty acid, hydroxyl fatty acid or $\alpha$-alkyl $\beta$-hydroxy fatty acid (Fig. 1).

\section{CMC VALUE OF SURFACTANT/BIOSURFACTANT: A KEY FOR CONSIDERATION OF POTENTIAL INDUSTRIAL APPLICA- TIONS}

The critical micelle concentration (CMC) is defined as the concentration of surfactant/biosurfactant at which organized molecular structures popularly known as 'micelles', are formed which relates the point at which the surface active compound attains the lowest but stable surface tension (SFT) further which there is no reduction in SFT values [14]. Thus characteristically formation of colloidal sized clusters in solution are generally known as 'micelle' which is happening due to the molecular structure of having both hydrophobic and hydrophilic moieties in each surfactant. Surfactant molecules are dispersed as monomers in the aqueous solution and slowly form aggregates (micelles), or can get adsorbed as a film at the air and water interface. Between these states; the surfactant is in dynamic equilibrium condition. The concept of micelle formation was first introduced by McBainin 1913, however, the foremost concrete model of spherical shaped micelles was put forward by Hartley [15]. Solubilization of surfactant in water insoluble ambiance is navigated by its CMC value. Thus the multifunctionality of surfactant is facilitated because of their physical properties like SFT, interfacial tension (IFT), wetting, spreading capabilities. In addition, other properties like $\mathrm{pH}$, temperature, ionic strength/electrical conductivity do have direct impact in determining the applications of surfactant for commercial purposes. The particle nucleation mechanism supported from Smith Ewart's theory states that the number surfactant particles nucleated is proportional to its concentration to the 0.6 power [16].

Each surfactant has its own CMC value in aqueous solution. At room temperature anionic surfactant tentatively exhibit a CMC value of $\sim 10^{-3}$ to $10^{-2} \mathrm{M}$ and for amphoteric and cationic surfactants it may be $\sim 10^{-3}$ to $10^{-1} \mathrm{M}$. For nonionic surfactants it is $\sim 10^{-5}$ to $10^{-4} \mathrm{M}[17,18,19]$. Some of the $\mathrm{CMC}$ values of popularly used surfactants/biosurfactant are shown in Fig. 2. There are several factors (summarized in Fig. 3) that increases or decreases the CMC value of respective surfactant.

The CMC value of surfactant/biosurfactant is a key to open its industrial perspectives. Cleaning, detergency and solubilization properties are determined by its $\mathrm{CMC}$ values and molecular structure. All different types of anionic, cationic, zwitterionic, nonionic surfactants facilitate recovery of residual oil and cleaning of oil contaminated sediments [23]. Surfactant molecules needs to get adsorbed at interfaces of foams, emulsions, surface coatings. During wetting, foaming, solubilization and emulsification process, the interfacial area increases very rapidly by addition of surfactant monomers. Monomers get adsorb initially to the freshly created interface and then, additional monomers further breaks the micelles. This situation is true when concentration of monomer is less and the micelle breakup time to the newly formed interface is not adequate to supply monomers. Under such circumstances, CMC value provides best and simplest opportunity to design several formulations. It is important to highlight that the CMC is significant to characterize colloid and surface behavior of a surfactants and therefore determining their suitability/usefulness for industrial purposes. a)

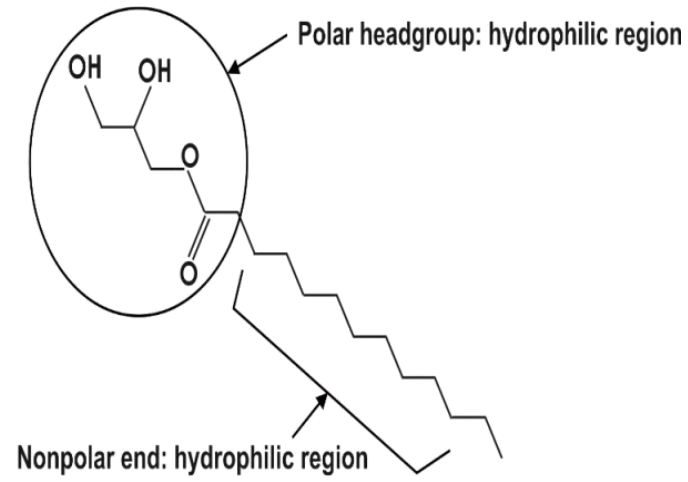

b)

1<smiles>CCCCCCCCCCCCCCCOCC(=O)O</smiles>

2<smiles>CCCCCCCCCCCCCCN(C)C</smiles>

3

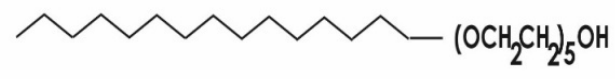

$4 \sim-\mathrm{CH}_{2} \mathrm{COO}$

Fig. 1 General structure of biosurfactants (a); Structures of some representative biosurfactants (b): 1 - anionics (carboxylate, sulfate, phosphate polar head groups), 2 - cationics (amine polar head groups), 3 - non-ionics; 4-zwitterionics (contain both, an anionic and a cationic, charge) 


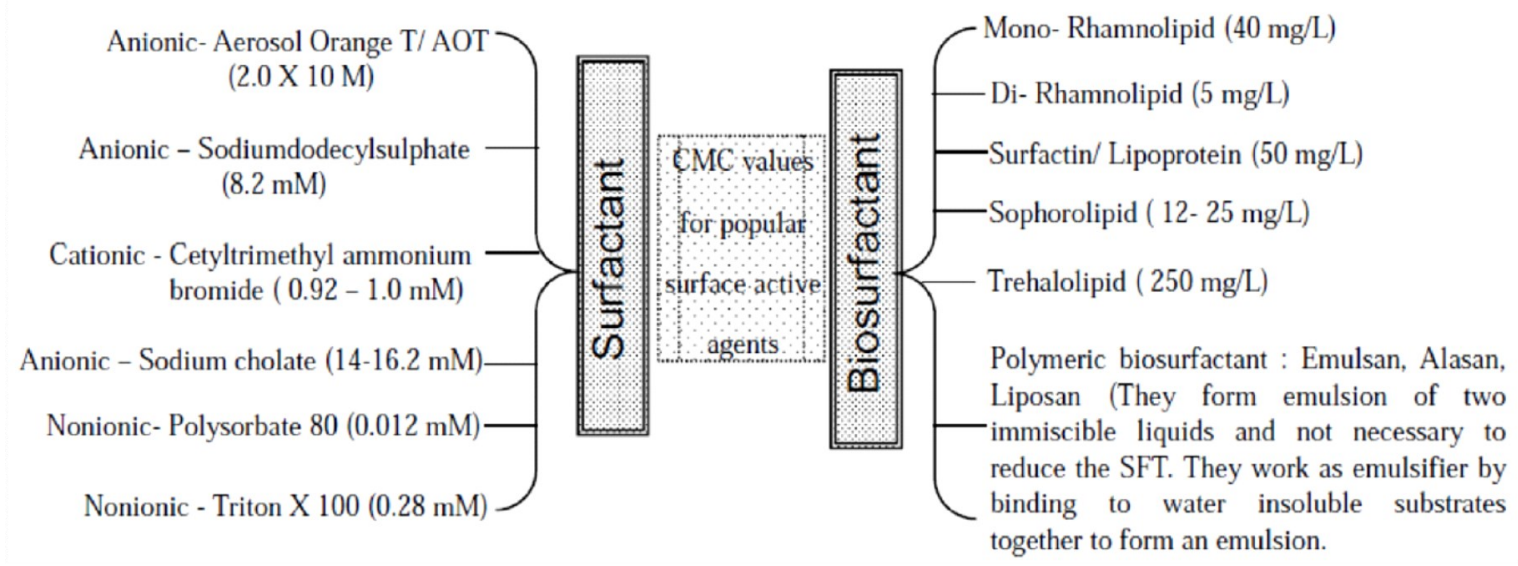

Fig. 2 Representative examples for critical micelle concentration (CMC) values of commercial used surfactants and biosurfactants Note: Depending upon the type, molecular structure/functional groups of biosurfactant, there is variation in their CMC values

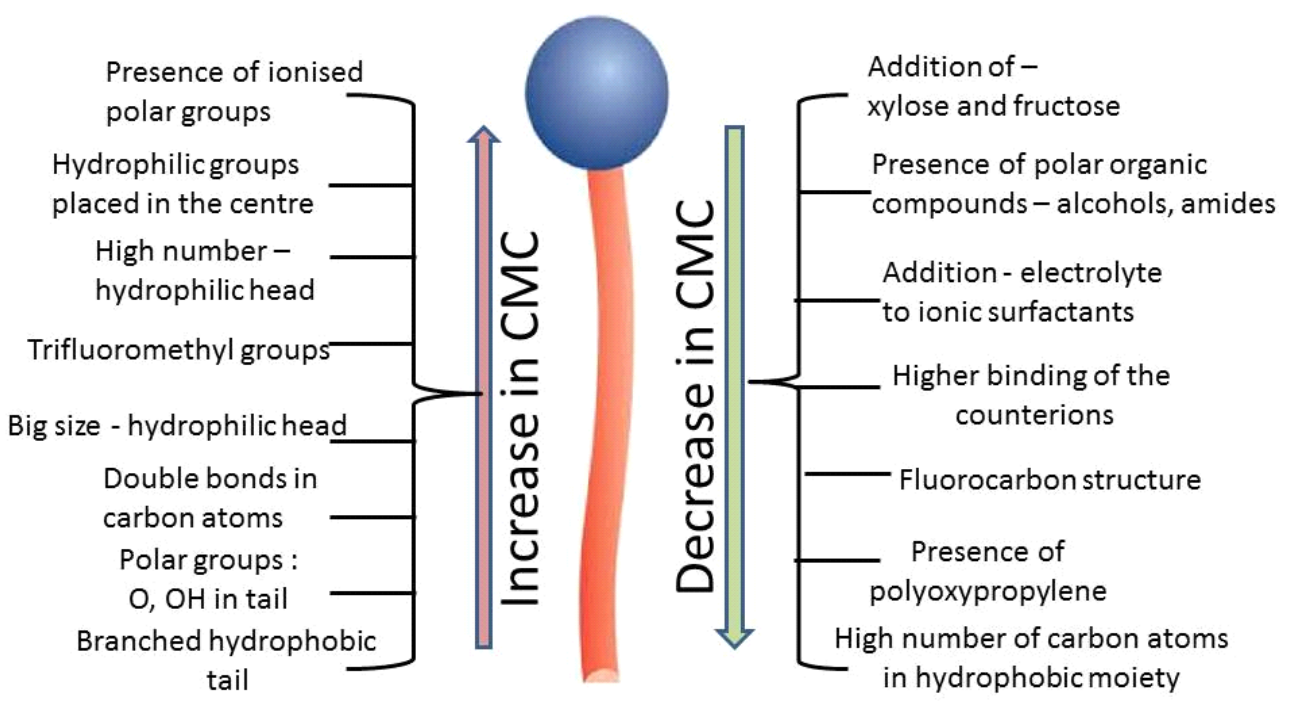

Fig. 3 Depiction of several factors leading to increase or decrease in CMC value of surfactant

Source: Based on [17, 19, 20, 21, 22].

\section{COST EFFECTIVE RENEWABLE NATURAL RESOURCES USED IN THE BIOSURFACTANT PRODUCTION: EXAMPLES}

This section regarding commercial biosurfactant production is discussed quite frequently in the literature which can be reasoned as the major difference in the monetary inputs and actual financial gain. Since the extraction and purification procedures used to recover biosurfactant are actually stealing the huge production cost during downstream processes. Consequently, researcher has suggested the usage of several effective renewable natural resources to overcome the financial crises in biosurfactant production industries. Currently substrates like wheat straw, rice straw, cassava, cassava flour sugarcane molasses, bagasse of sugarcane, beet molasses, bran and corn (Fig. 4) are available for biosurfactant production at commercial level [9].

Around the globe, most of the countries are showing tremendous awareness for environmental pollution and thereby much of the efforts are seen towards the development of newer and advanced technologies to encourage the cleaning of hazardous contaminants. The concern for green, eco-friendly environment is the main driving force to introduce novel approaches towards pollution handling issues.

Diverse types of water soluble and water insoluble carbon, nitrogen sources are used for intra or extra cellular, cell associated biosurfactant production. The chemical composition of biosurfactant is completely based on carbon and nitrogen sources used during its fermentation process $[24,25]$. Among all different available water soluble sources, glucose is used routinely in the literature. Water insoluble substrates like hydrocarbons and oils are also found to be economically feasible and supportive for growth of microbes [26, 27]. In addition, other unconventional substrates viz., blended gasoline, hydrocarbons like heptadecane, hexadecane, ethanol etc. offer greater hopes for biosurfactant production industries [28, 29, 30, 31, 32]. It may be necessary to treat the waste substrates before they are actually used for the purpose intended. For example, molasses needs to be clarified in order to remove unfavorable components that can interfere in the final product [31]. Molasses is clarified by diluting with water and further it is acidified (7.0) with the help of $\mathrm{CaO}$ and $\mathrm{K}_{4} \mathrm{Fe}(\mathrm{CN})_{6}$. On the other hand few raw substrates like rice water, a byproduct from food processing industries can be used directly, without much processing. Since rice water is also available abundantly and therefore represents as one of the easily available resources. Starch rich waste obtained after processing the cereals, pulses, accessed are most suitable nutritive sources for growth of microbes and for production of biosurfactant. 


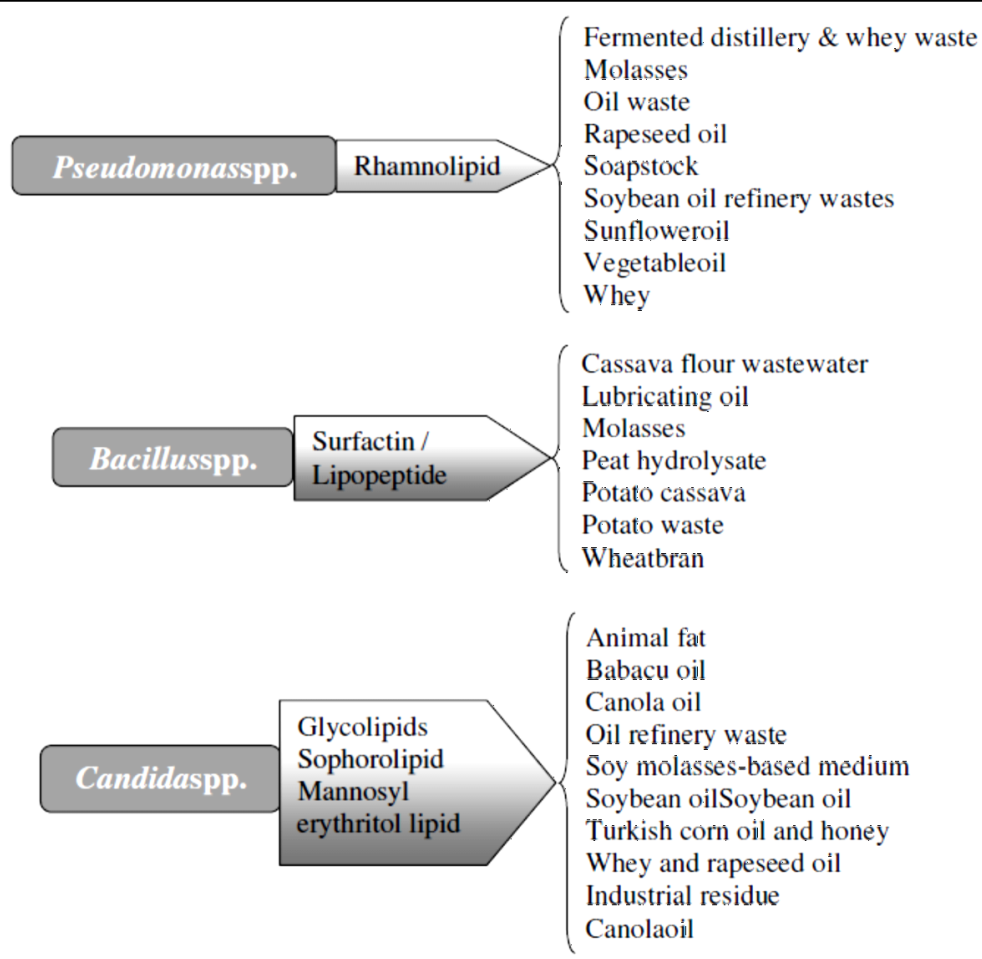

Fig. 4 Summary for diverse renewable substrates used for production of popularly known biosurfactant

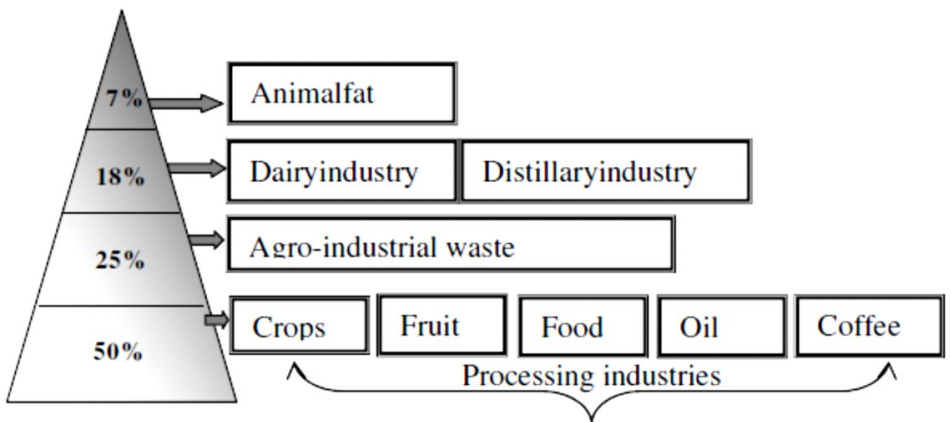

Fig. 5 Percentage distribution of renewable substrates available from several industries used for biosurfactant production. Source: Based on [32].

It is very important to recycle and reuse various renewable substrates as ingredients to recover industrial scale products. This apprehension is dynamic to encourage research particularly in management of wastes, effluents or by products which comes from various foods, agriculture sectors [9]. The aim with high quality product but at lower cost can be fulfilled with these approaches to meet financial predicament [10]. At the same time it is very important to choose top quality substrates in terms of nutritional value that can allow the growth of desired microorganism with plentiful production of biosurfactant. Barros et al. [33] recommended the use of agro-industrial waste predominantly to execute biosurfactant production efficiently. Literature scenario depicted in Fig. 5 indicates that food processing industries presents huge number of renewable substrates followed by agriculture industries (25\%).

Animal fat, dairy and distilleries have not been explored thoroughly and hence needs to be investigated further. One of the steps towards this approach is make use of abundantly available renewable substrates for biosurfactant production and facilitating the treatment of contaminants. Solid state fermentation based process has provided alternative approaches to yield more economical production of commercially important products [34]. Some of the renewable substrates used to yield biosurfactant are listed in Table 1. Some of the suggested strategies included the use of more cheap materials, optimization of environmental parameters and effective screening procedures to find out overproducing strain in order to attain the maximum productivity.

\section{Rhamnolipid (RHL)}

It is one of the well-known characterized low molecular weight biosurfactant where sugar moiety linked with fatty acid chain. The name rhamnolipid (RHL) is due to presence of its rhamnose moiety produced from $\mathrm{P}$. aeruginosa (formerly known as Pseudomonas pyocyanea) $[48,49,50]$. Literature since Jarvis \& Johnson [51], Hisatsuka et al. [52] since 1971 till today has discussed RHL production thoroughly. Number of different water soluble and water insoluble carbon, nitrogen sources has been utilized for commercial scale biosurfactant production from several Pseudomonas spp. The RHLs are the most current generation of biosurfactants which has occupied the global market. Literature scenario suggests that considerably high number of current publications and patents are mostly dedicated to glycolipid biosurfactants where RHLs have been studied thoroughly [53]. 
Table 1

Representative examples for renewable substrates used to yield biosurfactant

\begin{tabular}{|c|c|c|c|c|}
\hline Organism & Cheap/Renewablesubstrate & $\begin{array}{c}\text { Biosurfactant } \\
\text { type }\end{array}$ & $\begin{array}{l}\text { Yield } \\
\mathrm{g} / \mathrm{L}\end{array}$ & Reference \\
\hline P.aeruginosa & Molasses\&corn Steep liquor & Rhamnolipid & 0.24 & [35] \\
\hline P.aeruginosa & Distillery effluent and whey waste & Rhamnolipid & 0.91 & [36] \\
\hline $\begin{array}{l}\text { P.aeruginosa } \\
\text { mutant strain }\end{array}$ & Blackstrap molasses & Rhamnolipid & 1.45 & [31] \\
\hline P.aeruginosastrain LBI & Medium with Soapstock & Rhamnolipid & 15.9 & [37] \\
\hline $\begin{array}{l}\text { P.aeruginosaEBN-8 } \\
\text { mutantstrains }\end{array}$ & canola, soybean, corn oil refineries & Rhamnolipid & 8.50 & [38] \\
\hline Lactobacillusfermentum & $\begin{array}{l}\text { Hemicellulosic sugar hydrolyzates from vine } \\
\text { shoots }\end{array}$ & Biosurfactant & 0.71 & [39] \\
\hline Lactobacillusfermentum & Branhuskhydrolyzates & Biosurfactant & 0.28 & [39] \\
\hline C. bombicola & Mixture of glucose and fat $(10 \% \mathrm{w} / \mathrm{v})$ & Sophorolipid & 120 & {$[40]$} \\
\hline C. bombicola 22214 & Whey in combination with rapeseed oil & Sophorolipid & 280 & [41] \\
\hline C. bombicola & Deproteinizedwheyconcentrate & Sophorolipid & 50 & {$[42,43]$} \\
\hline C. bombicola & Sugarcane molasses and soybean oil & Sophorolipid & 38.76 & [42] \\
\hline P.fluorescensMFS03 & crude oil enriched mangrove soil & Biosurfactant & 9.43 & {$[44]$} \\
\hline Torulopsisbombicola & Vegetableoil & Sophorolipid & 67 & {$[45]$} \\
\hline NevskiaramosaNA3 & Palmoilmilleffluent & Biosurfactant & 1.0 & [46] \\
\hline Azotobacterchroococcum & Peanutoilcake & Biosurfactant & 4.6 & [47] \\
\hline
\end{tabular}

In addition to oil effluents or waste frying oils; sunflower oil also represent as a potential carbon and energy sources in the production of microbial surfactants. The low chain length $(<\mathrm{C} 10)$ fatty acids undergoes modification during fermentation of BS and are incorporated in BS molecules synthesized by organisms [54]. P. aeruginosa was reported for glycolipid production by growing in sugar beet molasses where $32 \mathrm{~g} / \mathrm{L}$ or RHL was obtained from a total of $55.3 \mathrm{~g}$ waste dates/L $[55,56]$. Low cost materials namely corn steep liquor (CSL) in combination with molasses has been utilized by several researchers for biosurfactant production from Pseudomonas strains. About $3.2 \mathrm{~g} / \mathrm{L}$ of $\mathrm{RHL}$ has been achieved with those low cost materials [55]. Another report from Monteiro et al. [57] suggested that about $3.9 \mathrm{~g} / \mathrm{L}$ of RHL biosurfactant can be achieved from P. aeruginosa DAUPE 614 in a culture medium supplemented with glycerol (sole carbon source) and ammonium nitrate (nitrogen) where C:N ratio of 55:1.Patel and Desai [35] had used $\mathrm{P}$. aeruginosa GS3 for production of RHL by growing culture in a medium supplemented with molasses $(7 \% \mathrm{v} / \mathrm{v})$ and CSL $(0.5 \% \mathrm{v} / \mathrm{v})$. Olive Oil Mills (OOM) produces concentrated black liquor syrup (water-soluble portion of ripe olives) which is one of the major concerns for agriculture sector. Toxic polyphenols are present in OOM effluents and therefore researchers are facing difficulties for their disposals. OOME contains sugars (20 to $80 \mathrm{~g} / \mathrm{L}$ ), nitrogen compounds (12 to $24 \mathrm{~g} / \mathrm{L}$ ), organic acids (5 to $15 \mathrm{~g} / \mathrm{L}$ ) and residual oil ( 0.3 to $5 \mathrm{~g} / \mathrm{L})$. This composition of OOME generally depends on climatic conditions, geographical origin, variety of olive and procedures used for olive oil-extraction. Mercade et al. [58] used OOME for the strain Pseudomonas sp. JAMM to produce RHLs. Authors tried to simplify the downstream processes through foam formation to recover industrial products. Foam formation was achieved by pumping the air into a reservoir filled with the supernatant of the culture containing $1.4 \mathrm{~g} / \mathrm{L}$ of RHLs. Further researchers collected foam in another reservoir and liquefied. Currently disposing procedures of OOME sounds economically good.

Improved yield of biosurfactant can be achieved from mutant strains $P$. aeruginosa on vegetable oil refinery wastes [59]. It is not mandatory that each time only recycled or used waste frying oil only can prove as good substrates. Cooking oil is a rich energy source to produce a high amount of RHLs proving to be as alternative sources from the food industry for production of mixture of mono and di- RHL from P. aeruginosa D [60].

Surfactin/Lipopeptide: Review of literature illustrates that like similar to Pseudomonas spp., Bacillus strains have been explored thoroughly for surfactin/lipoprotein production. Makkar and Cameotra [61] showed surfactin production from two Bacillus subtilis cultures in a production medium supplemented with molasses and noticed optimum BS production with good emulsification activity (EA) in late stationary phase. On similar lines, Joshi et al. [62] produced BS from several Bacillus strains under thermophilic conditions by using various combinations of molasses $(5.0-7.0 \%$ $\mathrm{w} / \mathrm{v}$ ) with whey to achieve high yields of BS.

In addition to the molasses, CSL or oil industries, starch based industries has provided ample of substrates where starch from potato processing industries is one of the greatest attraction for many researchers. The potato waste contains $\sim 80 \%$ of water content along with protein $(2 \%)$, carbohydrates $(17 \%)$, fat $(0.1 \%)$, inorganic minerals, vitamins, trace elements and therefore, can support growth and production of commercially grade products. Fox and Bala [63] used potato based mineral salts medium for BS production using strain of B. subtilis ATCC 21332 and found significant reduction in SFT (71.3 to $28.3 \mathrm{mN} / \mathrm{m}$ ) with a low CMC value $(0.10 \mathrm{~g} / \mathrm{L})$. Other research group of Thompson et al. [64], proposed use of potato effluents for production of 
surfactin from Bacillus spp. Since potato contains highsolids (HSs) and low-solids (LSs) authors recommended to dilute its10 times and to be supplemented with or without trace minerals.

Sophorolipids (SPLS): In addition to RHL and surfactin, sophorolipid (SPL) is other type of BS that has been investigated frequently and also occupies major part in the market as cleaning agent [11]. SPL production from whey is a common practice in biosurfactant industry. Daniel et al. [65] proposed that when whey is used, there is decrease in the lactose content and biological oxygen demand in the fermentation process. Authors conducted two-step batch cultivation experimental set up where, sterilization of whey was mediated via cross flow and sterile filtration and during SPLs production from Candida bombicola ATCC 22214 strain do not use lactose. Authors also grew oleaginous yeast Cryptococcus curvatus ATCC 20509 on deproteinized whey concentrates (DWC) which is necessary to dilute (1:1). These studies showed SPL production from $12 \mathrm{~g} / \mathrm{L}$ of the yeast $C$. bombicola. High yield of SPL was achieved by Daniel et al. $[41,65]$ on whey concentrate and rapeseed oil in absence without consumption of any lactose.

The Candida strain ATCC 22214 has been used by many authors to demonstrate the use of renewable substrates for SPLs production. Kim et al. [66] utilized soybean dark oil a byproduct of soybean oil processing industries and achieved $90 \mathrm{~g} / \mathrm{L}$ of SPLs in a fed-batch culture process. The SPLs reduces SFT to about $48 \mathrm{mN} / \mathrm{m}$ with a CMC value of $150 \mathrm{mg} / \mathrm{L}$. The SPLs can disperse to greater extent in comparison with chemical surfactants like SDS and Brij30 and SPLs also do possess great antimicrobial activity against bacterial strains like Propionibacterium acne and B. subtilis.

Elshafie et al. [67] recently demonstrated biosurfactant producing C. bombicola ATCC 22214, for potential applications in oil recovery process. Production medium designed with glucose $(2 \% \mathrm{w} / \mathrm{v})$ and corn oil $(10 \% \mathrm{v} / \mathrm{v})$ successfully utilized by ATCC 22214 and demonstrated reduction in SFT $(28.56+0.42 \mathrm{mN} / \mathrm{m})$ and IFT $(2.13+0.09 \mathrm{mN} / \mathrm{m})$. SPLs are quite stable at $13-15 \%$ salinity, $\mathrm{pH}$ of wide range (2-12), and temperature upto $100^{\circ} \mathrm{C}$. Elshafie et al. [67] were successful to demonstrate the role of SPLs in enhancing oil recovery (27.27\% of residual oil (Sor) recovery) using core-flooding experimental set up under reservoir conditions.

Waste water resulting from dairy industries shows presence of high fat and oil content and therefore disposal of these effluents is extremely challenging. It is very difficult to handle these wastes by biological means to get rid of and therefore, the pretreatments of dairy waste water are critical issues. Daverey and Pakshirajan [68] worked with synthetic dairy waste water preparation for growth of C. bombicola in batch, fed-batch, and continuous fermentation process. In addition to synthetic dairy water, carbon source such as sugarcane molasses $(1 \% \mathrm{w} / \mathrm{v})$ and nitrogen source as yeast extract $(0.1 \% \mathrm{w} / \mathrm{v})$ can be incorporated to enhance the yield of biosurfactant. Their studies resulted > 93\% chemical oxygen demand (COD) removal which is disappearances of fats wastewater. Such encouraging results opens wide ways for disposal of wastes is effective ways.

\section{TECHNOLOGICAL RELATED ASPECTS OF BIOSURFACTANT PRODUCING INDUSTRIES}

Industrial sectors seems to be interested in manufacturing or producing the clean products and processes through the consideration of market scenario and/or production cost of commercially important products. The technological innovations determines the sustainability and possible capital income of respective industry. Decisions towards commercial strategic development always plays a crucial role in making its bench mark in the domestic as well as international level market. At the same time, it also important to note that it may not be always possible or easier to implement the clean processing technologies to gain economic benefits. Biosurfactant derived from various microbial sources by using various raw substrates, cannot be escaped from the above explained issues. Even with biosurfactant offers number of advantages over synthetic surfactant, the financial side of biosurfactant production has been ignored or has not received adequate consideration. Therefore, it is the need of the hour to look in biosurfactant industrial sectors in order to strive in the surfactant market against chemical surfactants $[69,70]$. The major hindrance for large scale production of biosurfactants at industrial scale is due to their excessive production cost (10-30\%) as compared with synthetic surfactants [71]. This situation is extremely challenging.

\section{CONCLUSIONS}

Designing the new strategies and technologies is the need of the hour in order to minimize the production cost of biosurfactant at commercial scale and make the production process economically competitive. Eminent scientists are utilizing the approaches like green chemistry and genetic engineered of microorganisms to enhance the yield and quality of the biosurfactant product. Pretreatment of renewable substrates makes easy for the growth of organism easily. But care should be taken not to lose the nutritional values of such substrates. Since the quality as well as quantity wise the product is very much mandatory to open up broad industrial perspectives for microbial origin surface active agents. Tremendous scope for wastes from food processing, animal fats and dairy industrial sectors is still waiting to be explored.

Dr. Surekha Satpute acknowledges Department of Science and Technology (DST), Ministry of Science and Technology, Government of India, New Delhi for financial support vide reference no. $\{S R / W O S-A / L S-1076 / 2014(G)\}$ under Woman Scientist Scheme (WOS-A) to carry out this research work. Constant support from the Director, School of Basic Medical Sciences, Department of Physics, Savitribai Phule Pune University is also acknowledged. This paper is connected with the project no 13/030/BK_16/0024 entitled "Production engineering methods and tools for development of smart specializations" financed by the Ministry of Science and Higher Education"

\section{REFERENCES}

[1] "Innovating for Sustainable Growth: A Bioeconomy for Europe", COM, Brussels, 2012.

[2] A.R.C. Morais and R. Bogel-Lukasik. "Green chemistry and the biorefinery concept", in Sustainable Chemical Processes, vol. 1(18), 2013, pp. 56-69.

[3] F. Fava, G. Totaro, L. Diels et al. „Bio waste biorefinery in Europe: opportunities and research and development needs", in New Biotechnology, vol. 32(1), 2015, pp. 100-108. 
[4] Joint European Biorefinery Vision for 2030. Star COLIBRI - Strategic targets for 2020 - collaboration initiative on biorefineries, 2011.

[5] F. Cherubini. „The biorefinery concept: using biomass instead of oil for producing energy and chemicals", in Energy Convers Management, vol. 51(7), 2010, pp. 1412-1421.

[6] E. de Jong, R. van Ree, I.K. Kwant et al. „Biorefineries: Adding Value to the Sustainable Utilisation of Biomass", in IEA Bioenergy, vol. 1, 2009, pp. 1-16.

[7] T. Gabrielczyk. "Can Europe stop the stream of wastes?", in European Biotechnology, vol. 15, 2016, pp. 50-55.

[8] L.A. Pfaltzgraff and J.K. Clark. „Green chemistry, biorefineries and second generation strategies for re-use of waste: an overview", in Advances in Biorefineries, K. Waldron, Cambridge: Woodhead Publishing Limited, 2014, pp. 3-33.

[9] I.M. Banat, S.K. Satpute, S.S. Cameotra, R. Patil and N.V. Nyayanit. "Cost effective technologies and renewable substrates for biosurfactants' production”, in Frontiers in Microbiology, vol. 5, 2014, pp. 697-708.

[10] R.S. Makkar and S.S. Cameotra. „An update on the use of uncoventional substrates for biosurfactant production and their new applications", in Applied Microbiology and Biotechnology,vol. 58(4), 2002, pp. 428-434.

[11] C.N. Mulligan, S.K. Sharma and A. Mudhoo. Biosurfactants. Research Trends and Applications, Boca Raton: CRC Press, Taylor\&Francis Group, 2014.

[12] A.A. Bodour and R.M. Maier. „Biosurfactants: types, screening methods and applications", in Encyclopedia of Environmental Microbiology, vol. 2, New York: John Wiley \& Sons Inc., 2001, pp. 750-770.

[13] G. Soberon-Chavez. Biosurfactants: From genes to applications, Berlin-Heidelberg: Springer-Verlag Berlin Heidelberg, 2011.

[14] J.M. Campos, T.L.M. Stamford, L.A. Sarubbo et al. „Microbial biosurfactants as additives for food industries", in Biotechnology Progress, vol. 29(5), 2013, pp. 1097-1108.

[15] G.S. Hartley. Aqueous solutions of paraffin chain salts. A study in micelle formation, Paris: Hermann et Cie, 1936.

[16] L.S. Romsted. „Micellar Catalysis of Diels-Alder Reactions: Substrate Positioning in theMicelle, in Micellization solubilsation and micro emulsions, vol. 2, K.L. Mittal, New York: Plenum Press, 1977, pp. 95-119.

[17] M.J. Rosen. Surfactant and interfacial phenomena, 3rded., New York: Wiley, 2004.

[18] P. Mukerjee and K.J. Mysels. „Critical micelle concentrations of aqueous surfactant systems nonionic detergents", no NSRDS-NBS 36, National Standard Reference Data System, 1971.

[19] R. Mandavi. „Kinetic studies of some esters and amides in presence of micelles", chapter 2, Ph.D. dissertation, Pt. Ravishankar Shukla University Raipur (CG), India Department of Chemistry, 2011.

[20] M.R. Porter. Handbook of Surfactants, 2nd ed., London: Chapman \& Hall, 1994.

[21] A.L. Hunter. Foundations of colloid science, vol. 1-2, Oxford: Clarendon, 1987.

[22] A. Ray and G. Nemethy. „Effects of ionic protein denaturants on micelle formation by nonionic detergents", in Journal of American Chemical Society, vol. 93(25), 1971, pp. 6787-6793.
[23] M.M. Rieger. „The Skin irritation potential of quaternaries", in Journal of the Society of Cosmetic Chemists, vol. 48, 1997, pp. 307-317.

[24] M.E. Mahmood and D.A.F. Al-Koofee. „Effect of temperature changes on critical micelle concentration for Tween series surfactant", in Global Journal of Science Frontier Research. Chemistry, vol. 13(4), 2013, pp. 1-5.

[25] L.H. Guerra-Santos, O. Kappeli and A. Fiechter. „Dependence of Pseudomonas aeruginosacontinuous culture biosurfactant production on nutritional and environmental factors", in Applied Microbiology and Biotechnology, vol. 24(6), 1986, pp. 443-448.

[26] A. Fiechter. „Biosurfactants: moving towards industrial application", in Trends Biotechnology, vol. 10, 1992, pp. 208-217.

[27] C. Syldatk and F. Wagner. „Production of biosurfactants", in Biosurfactants and Biotechnology, N. Kosaric, W.L. Cairns and N.C.C. Gray, New York: Marcel Dekker Inc., 1987, pp. 89-120.

[28] S.K. Satpute, S.S.Bhuyan, K.R. Pardesi et al. „Chapter 2: Molecular Genetics of Biosurfactant Synthesis in Microorganisms", in Biosurfactants, R. Sen, New York: Springer-Verlag New York, 2010.

[29] Y. Prabhu and P.S. Phale. „Biodegradation of phenanthrene by Pseudomonas sp. strain PP2: novel metabolic pathway, role of biosurfactant and cell surface hydrophobicity in hydrocarbon assimilation", in Applied Microbiology and Biotechnology, vol. 61(4), 2003, pp. 342-351.

[30] C.D. Cunha, M. Rosario, A.S. Rosado and G.F. Leite. „Serratiasp. SVGG16: Apromising biosurfactant producer isolated from tropical soild during growth with ethanol blended gasoline", in Process Biochemistry, vol. 39, 2004, pp. 2277-2282.

[31] Z.A. Raza, M.S. Khana, Z.M. Khalidb and A. Rehman. „Production of biosurfactant using different hydrocarbons by Pseudomonas aeruginosa, in Journal of Biosciences: vol.61(1-2), 2006, pp. 87-94.

[32] Z.A. Raza, M.S. Khan and Z.M. Khalid. „Physicochemical and surface active properties of biosurfactant produced using molasses by a Pseudomonas aeruginosa mutant", in Journal of Environmental Science and Health. Toxic Hazardous Substances and Environmental Engineering, vol. 42(1), 2007, pp. 73 80.

[33] F.F.C. Barros, C.P. Quadros, M.R. Maróstica and G.M. Pastore. „Surfactina: Propriedades químicas, technológicas e funciona is para aplicações em alimentos", in Química Nova, vol. 30(2), 2007, pp. 1-14.

[34] S.G. Kapadia and B.N. Yagnik. „Current trend and potential for microbial biosurfactants", in Experimental Biological Science, vol. 4, 2013. pp. 234-251.

[35] R.M. Patel and A.J. Desai. „Biosurfactant production by Pseudomonas aeruginosa GS3 from molasses”, in Letter Applied Microbiology, vol. 25, 1997, pp. 91-94.

[36] K. Dubey and A. Juwarkar. „Distillery and curd whey wastes as viable alternative sources for biosurfactant production", in World Journal of Microbiology and Biotechnology, vol. 17, 2001, pp. 61-69.

[37] M. Benincasa, J. Contiero, M.A. Manresa and I.O. Moraes. „Rhamnolipid production by Pseudomonas aeruginosa LBI growing on soap stocks the sole carbon source", in Journal of Food Engineering, vol. 54(4), 2002, pp. 283-288. 
S. K. SATPUTE, G. A. PŁAZA, A. G. BANPURKAR - Biosurfactants' production from renewable natural resources: example...

[38] Z.A. Raza, A. Rehman, M.S. Khan and Z.M. Khalid. „Improved production of biosurfactant by a Pseudomonas aeruginosa mutant using vegetable oil refinery wastes", in Biodegradation, vol. 18, 2007, pp. 115121.

[39] A.B. Moldes, A.M. Torrado, M.T. Barral and J.M. Domínguez. „Evaluation of biosurfactant production from various agricultural residues by Lactobacillus pentosus", in Journal of Agriculture and Food Chemistry, vol. 55(11), 2007, pp. 4481-4486.

[40] M. Deshpande and L. Daniels. „Evaluation of sophorolipid biosurfactant production by Candida bombicola using animal fat", in Bioresource Technology, vol. 54, 1995, pp. 143-150.

[41] H.J. Daniel, M. Reuss and C. Syldatk. „Production of sophorolipids in high concentration from deproteinized whey and rapeseed oil in a two stage fed batch process using Candida bombicolaATCC22214 and Cryptococcus curvatusATCC20509", in Biotechnology Letter, vol. 20, 1998, pp. 1153-1156.

[42] H.J. Daniel, R.T. Otto, M. Binder, M. Reus and C. Syldatk. „Production of sophorolipids from whey: development of a two-stage process with Cryptococcus curvatusATCC20509 and Candida bombicolaATCC22214 using deproteinized whey concentrates as substrates", in Applied Microbiology and Biotechnology, vol. 51(1), 1999, pp. 40-45.

[43] A. Daverey, K. Pakshirajan and P. Sangeetha. „Sophorolipids production by Candida bombicola using synthetic dairy waste water", in World Academy of Science, Engineering and Technology, vol. 3, 2009, pp. 470-472.

[44] M. Govindammal and R. Parthasarathi. „Biosurfactant production using pineapple juices medium by Pseudomonas fluorescens isolated from mangrove forest soil", in Indian Streams Research Journal, vol. 2(12), 2013, pp. 1-10.

[45] D.G. Cooper and D.A. Paddock. „Production of a biosurfactant from Torulopsis bombicola", in Applied Environment, vol. 47(1), 1984, pp. 173-176.

[46] C.S. Chooklin, S. Phertmean, B. Cheirsilp, S. Maneerat and A. Saimmai. „Utilization of palm oil mill effluent as a novel and promising substrate for biosurfactant production by Nevskia ramosaNA3", in Songklanakarin Journal of Science and Technology, vol. 35(2), 2013, pp. 167-176.

[47] R. Thavasi, V.R.M. Subramanyam Nambaru, S. Jayalakshmi, T. Balasubramanian and I. M. Banat. „Biosurfactant production by Azotobacter chroococcum isolated from the marine environment", in Marine Biotechnology, vol. 11, 2009, pp. 551-556.

[48] S.K. Satpute, B.D. Bhawsar, P.K. Dhakephalkar and B.A. Chopade. „Assessment of different screening methods for selecting biosurfactant producing marine bacteria", in Indian Journal of Marine Sciences, vol. 37(3), 2008, pp. 243-250.

[49] S. Bergström, H. Theorell and H. Davide. „On a metabolic product of Ps. pyocyanea. Pyolipic acid, active against M. tuberculosis", in Archives of Chemistry, Mineralogy and Geology., vol. 23A (13), 1946, pp. 112.

[50] S. Bergström, H. Theorell and H. Davide. „Pyolipic acid. A metabolic product of Pseudomonas pyocyanea active against Mycobacterium tuberculosis", in Archives of Biochemistry and Biophysics, vol. 10, 1946, pp. 165166.

[51] F.G. Jarvis and M.J. Johnson. „A glycolipid produced by Pseudomonas aeruginosa", in Journal of American Chemical Society, vol. 71(12), 1949, pp. 4124-4126.

[52] K. Hisatsuka, T. Nakahara, N. Sano and K. Yamada. „Formation of rhamnolipid by Pseudomonas aeruginosa and its function in hydrocarbon fermentation", in Agricultural Biology Chemistry, vol. 35(5), 1971, pp. 686-692.

[53] M.G. Rikalović, M. Vrvić and M.I. Karadžić. „Rhamnolipid biosurfactant from Pseudomonas aeruginosa - from discovery to application in contemporary technology", in Journal of the Serbian Chemical Society, vol. 80(3), 2015, pp. 279-304.

[54] E. Haba, M.J. Espuny, M. Busquets and A. Manresa. „Screening and production of rhamnolipids by Pseudomonas aeruginosa 47T2 NCIB40044 from waste frying oils", in Journal of Applied Microbiology, vol. 88(3), 2000, pp. 379-387.

[55] M. Rashedi, M. Assadi, E. Jamshidi and B. Bonakdarpour. „Production of rhamnolipids by Pseudomonas aeruginosa growing on carbon sources", in International Journal of Enviornmental Science and Technology, vol. 3(3), 2006, pp. 297-303.

[56] E.J. Gudiña, A.I. Rodrigues, E. Alves et al. „Bioconversion of agro-industrial by-products in rhamnolipids toward applications in enhanced oil recovery and bioremediation", in Bioresource Technology, vol. 177, 2015, pp. 87-93.

[57] S.A. Monteiro, G.L. Sassaki, L.M. de Souza et al. „Molecular and structural characterization of the biosurfactant produced by Pseudomonas aeruginosa DAUPE 614", in Chemistry and Physics of Lipids, vol. 147(1), 2007, pp. 1-13.

[58] M.E. Mercade, A. Manresa, M. Robert et al. „Olive oil mill effluent (OOME) new substrate for biosurfactant production", in Bioresource Technology, vol. 43, 1993, pp. 1-6.

[59] Z.A. Raza, A. Rehman, M.S. Khan and Z.M. Khalid. „Improved production of biosurfactant by a Pseudomonas aeruginosa mutant using vegetable oil refinery wastes", in Biodegradation, vol. 18(1), 2007, pp. 115121.

[60] S. George and K. Jayachandran. „Production and characterization of rhamnolipid biosurfactant from waste frying coconut oil using a novel Pseudomonas aeruginosa D", in Journal of Applied Microbiology, vol. 114 (2). 2013, pp. 343-383.

[61] R.S. Makkar and S.S. Cameotra. „Utilization of molasses for biosurfactant production by two Bacillus trains at thermophilic conditions", in Journal of the American Oil Chemists' Society, vol. 74(7), 1997, pp. 887-889.

[62] S. Joshi, C. Bharucha, S. Jha et al. „Biosurfactant production using molasses and whey under thermophilic conditions", in Bioresource Technology, vol. 99(1), 2008, pp. 195-199.

[63] S.L. Fox and G.A. Bala. „Production of surfactant from Bacillus subtilis ATCC 21332 using potato substrates", in Bioresource Technology, vol. 75(3), 2000, pp. 235240.

[64] D.N. Thompson, S.L. Fox and G.A. Bala. "Biosurfactants from potato process effluents", in Applied Biochemistry and Biotechnology, vol. 84(1), 2000, pp. 917-930. 
[65] H.J. Daniel, R.T. Otto, M. Reuss and C. Syldatk. "Sophorolipid production with high yields on whey concentrate and rapeseed oil with consumption of lactose", inBiotechnology Letter, vol. 20, 1998, pp. 805 $-807$.

[66] H.S. Kim, Y.B. Kim, B.S. Lee and E.K. Kim. "Sophorolipid production by Candida bombicola ATCC 22214 from a corn oil processing by product", in Journal of Microbiology and Biotechnology, vol. 15(1), 2005, pp. 55-58.

[67] A. E. Elshafie, S.J. Joshi, Y.M. Al-Wahaibi et al. "Sophorolipids production by Candida bombicola ATCC 22214 and its potential application in microbial enhanced oil recovery", in Frontier Microbiology, vol. 6, 2015, pp. 1324-1337.

[68] A. Daverey and K. Pakshirajan. "Pretreatment of synthetic dairy waste water using the sophorolipid producing yeast Candida bombicola", in Applied Biochemistry and Biotechnology, vol. 163(6), 2011, pp. 720728.
[69] M. Nitschke M, Pastore, G. M. Biossurfactantes: Propriedades e aplicações. Quim Nova 25, 2002, pp. 772776.

[70] C. D. Coimbra, R. D. Rufino J. M. Luna, L. A. Sarubbo."Studies of the cell surface properties of Candida species and relation to the production of biosurfactants for environmental applications", Current Microbiology 58,2009, pp. 245-251.

[71] P. B. Singh and H. Singh Saini Biotransformation of Waste Biomass into High Value Biochemicals, Chapter: 18. Exploitation of agro-industrial wastes to produce low cost microbial surfactants, Publisher: Springer New York, Editors: Satinder Kaur Brar, Gurpreet Singh Dhillon, Carlos Ricardo Soccol, pp.445-471.

Dr Surekha K. Satpute, Arun G. Banpurkar

Center for Advanced Studies in Materials Science

and Condensed Matter,

Department of Physics, Savitirbai Phule Pune University

Pune 411007, Maharashtra, INDIA

Prof. dr hab. Grażyna A. Płaza

Silesian University of Technology, Faculty of Organisation and Management

Institute of Production Engineering

ul. Roosevelta 26-28, 41-800 Zabrze, POLAND

e-mail: grazyna.plaza@polsl.pl 